\title{
LOAD BALANCING LOCATION OF EMERGENCY MEDICAL SERVICE STATIONS
}

\author{
L'udmila Jánošíková, Lýdia Gábrišová, Bruno Ježek
}

\section{Introduction}

The quality and efficiency of an emergency medical system (EMS) depends mainly on the number of ambulances operating in a given region and the deployment of stations where the ambulances are kept. Specifying the proper number of ambulances is a sensitive issue balancing between two opposing aspects. On one hand, the main role of the EMS - to save lives and reduce human suffering caused by injuries or illnesses - requires a dense network of emergency stations. On the other hand, there is a justified requirement on the efficiency of public expenditures. In the Slovak Republic there is one ambulance at every station. The number and locations of stations in the whole state territory are defined by the Regulations of the Ministry of Health of the Slovak Republic No. 10548/2009-OL, 11378/2010OL and 14016/2010-OL. In accordance with the Regulations, 273 stations are currently deployed in the area of the Slovak Republic. The statistical computations that allocate each municipality to the nearest station suggest that there are significant differences in population in the regions served by individual ambulances, therefore some ambulances are used less frequently than the others. The accessibility of the emergency service in regions served by overloaded ambulances deteriorates, since the probability that the nearest ambulance will be busy at the moment of an emergency call is high. Assuming that the number of ambulances is given, we want to investigate whether locating ambulances differently might result in a more even distribution of their workload and, consequently, in a better performance of the system.

To design a new deployment of stations, a mathematical programming model constraining the population allocated to one station can be used. Out of the abundant number of location models, a capacitated p-median model has been chosen, since it maximises the efficiency of the system, but it simultaneously increases the fairness of the delivery of the EMS service. The efficiency criterion means that with a limited number of resources the best possible level of the service is provided to as many people as possible. In a p-median model, the total travel time of ambulances to potential patients is a surrogate of efficiency. Besides efficiency, equity (or fairness) is a core performance dimension in a health care system [17]. Fairness is achieved when each customer receives the service of required and/ or acceptable quality. This demand is hard to meet in a deterministic mathematical model because of the stochastic nature of the real system. Deterministic models of the EMS systems are based on an implicit assumption that there is always an ambulance available to respond to a call. But in the real system this may not be true because the arriving calls are stochastic events, and treating a patient is also a random variable. Moreover, the travel time of an ambulance may be affected by the traffic and weather conditions. Therefore, the nearest ambulance may happen to be busy when an accident occurs. Then another ambulance must be dispatched to serve the call, or the service must be postponed. Thus the real service level becomes lower than the computed one. However, we can limit the population allocated to one station in the problem formulation and so increase the probability that the nearest ambulance will be available at the moment of an emergency call.

The rest of the paper is organized as follow: Section 1 reviews the literature on location models in public service systems. A mathematical programming model for the capacitated p-median problem is formulated in Section 2. Section 3 describes two heuristic 
methods solving the problem and a new heuristic method based on previously developed approaches. The numerical evaluation of the solutions is presented in Section 4. The last section provides conclusions and presents some perspectives for future research.

\section{Literature Review}

We recommend the excellent paper by ReVelle and Eiselt [21] as an introduction to the location analysis. The authors distinguish two basic types of location problems: continuous location problems, which are for the most part planar problems and tend to be non-linear optimization problems, and discrete location problems, which are most often network problems, involve zeroone variables and result in integer programming optimization problems. Another classification of location problems differentiates between the private and public sectors. Regarding discrete location models in the public sector, we refer to [18] for the overview of basic models and [4] for the case study in the Slovak Republic. Ambulance location and relocation models are surveyed in [5]. In this review paper, the models are classified into two main categories: deterministic and probabilistic models.

Deterministic models are used at the planning stage. They ignore stochastic considerations regarding the availability of ambulances. They can be further divided into covering and allocation models. In covering models, a maximum value is preset for either distance or travel time. If a service is provided by a facility located within this limit, then the service is considered acceptable, and a customer is considered covered by the service, if he has a facility sited within the preset distance or time. There are two types of objective: we may want to cover all customers with minimum number of facilities or, given a limited number of facilities, to maximize coverage of the population. In the former case, the problem is called a Location Set Covering Problem (LSCP), in the latter case we are faced to a Maximal Covering Location Problem (MCLP). The concept of coverage for location of ambulances is used for example by Aringhieri et al. [2]. The authors propose the Lower-Priority Calls Coverage model to provide a lower bound on the number of ambulances needed to guarantee a desired level of the emergency service. In the allocation models, the goal is to assign demand zones to ambulance locations in order to minimise the total travel time from the ambulance locations to potential patients. One of possible models of this type is so-called $p$-median model that is solved in [7] and [22] to optimise ambulance locations in the city of Niigata (Japan).

Probabilistic models reflect the fact that ambulances operate as servers in a queuing system and they cannot always answer a call. Probabilistic models have been developed for example by Chanta et al. [6] or Ingolfsson et al. [12]. The basic concept in their approach is socalled busy fraction of ambulances, which is the probability that the ambulance will be occupied at the moment of the call reception, and it will not be able to respond to the call. The problem is that the busy fraction of an ambulance depends on the location of ambulances, more specifically on the region that is served by each ambulance, however, this is in fact the output from the location model. So the models that deal with the busy fractions as exogenous inputs cannot give a realistic output either, even if they are solved repeatedly in an iterative process, where the busy fractions of ambulances are adjusted according to the output of the previous iteration.

The way to cope with a temporal unavailability of the nearest ambulance is to involve a redundant ambulance. The concept of backup coverage was first introduced by Hogan and ReVelle [11]. Backup coverage means that a customer has at least two ambulances kept at disposal in their neighbourhood. Pirkul and Schilling [20] and Araz et al. [1] further expand the backup coverage formulation and consider workload capacities of facilities.

Most studies published so far deal with ambulance location in an urban area like Milano, Italy [2], Auckland Region, New Zealand [10], Belo Horizonte, Brazil [23], Niigata, Japan [7], [22]. However, our goal is to design a methodology applicable in a large-scale territory including both urban and rural areas. The methodology comprises a suitable mathematical programming model and a simulation model that is used to evaluate the performance of the system in a dynamic environment. The computer simulation performed with the solutions of different deterministic optimisation models [15] suggests that the p-median model for ambulance location in a large-scale territory outperforms backup coverage models in terms of expected average travel time, percentage of rescue calls accessible within 15 minutes and the number of calls that 
have to be put on hold. However, the p-median model leads to significant differences in the workload of individual ambulances. Therefore, it seems reasonable to limit the population allocated to one station. This restriction results in a fair distribution of ambulances' workload and, which is more important, in better availability of the ambulances. This way the problem of station location becomes a weighted capacitated p-median problem.

\section{Problem Formulation}

The goal in the weighted capacitated $p$-median problem is to find the location of a fixed number of $p$ stations in order to minimise the total travel time needed to reach all potential patients. The model for the load balancing station location preserves the current number of stations and looks for a new station location in the concerned region. The demand zones are individual villages and cities. We suppose that the demand (i.e. the number of emergency calls) in a municipality is proportional to the number of its inhabitants. Therefore, in the objective function the travel time of an ambulance from its base station to a municipality will be multiplied by the number of inhabitants. We assume deterministic travel times (defined by the distance and the average speed for a given road type). The average speed is based on the analysis by Ježek et al. [16].

The inputs to the mathematical programming model are as follow:

I the set of candidate locations,

$J$ the set of municipalities,

$\mathrm{p}$ the number of stations to be located,

$t_{i j}$ the shortest travel time of an ambulance from site $i \in I$ to site $j \in J$,

$b_{i}$ the number of the inhabitants of a municipality $\mathrm{j} \in \mathrm{J}$,

$Q$ the capacity limit of an ambulance.

The decision on opening a station (or more stations) in a candidate location $i \in I$ can be modelled by the nonnegative integer variable $y_{i}$. The value of $y_{i}$ is the number of stations located in centre $i$ (of course, it may be zero). The assignment of the municipality $j$ to the centre $i$ is modelled by a binary variable $x_{i j}$. The variable $x_{i j}$ takes value of 1 , if the municipality $j$ will be served by an ambulance located in the centre $i$, otherwise $x_{i j}=0$.

After these preliminaries, the model of the weighted $p$-median problem can be written as:

$$
\begin{aligned}
\text { Minimise } & \sum_{i \in I} \sum_{j \in J} t_{i j} b_{j} x_{i j} \\
\text { Subject to } & \sum_{i \in I} x_{i j}=1 \quad \text { for } j \in J \\
& x_{i j} \leq y_{i} \quad \text { for } i \in I, j \in J \\
& \sum_{j \in J} b_{j} x_{i j} \leq Q y_{i} \quad \text { for } i \in I \\
& \sum_{i \in I} y_{i}=p \\
& y_{i} \in Z_{0}^{+} \quad \text { for } i \in I \\
& x_{i j} \in\{0,1\} \quad \text { for } i \in I, j \in J
\end{aligned}
$$

The basic system criterion (1) is the total travel time of ambulances to all potential patients (or inhabitants of municipalities). Constraints (2) ensure that every municipality $j$ will be assigned to exactly one centre $i$. Constraints (3) ensure that if the municipality $j$ is assigned to the centre $i$, then at least one station must be open in that centre. Constraints (4) limit the total number of persons served by one centre. Constraint (5) limits the total number of the stations that can be sited. The remaining obligatory constraints (6) and (7) specify the definition domains of the variables.

The capacitated $p$-median problem is known to be NP-complete. As a consequence, it cannot be solved to optimality even for moderatesized problem instances [13]. However, we face a large-scale problem instance consisting of all 2,916 municipalities in Slovakia (by the administrative division valid in 2003). Every municipality is regarded as a candidate location, as well as a demand zone, it means $I=J$ and $|I|=|J|=2,916$.

To get a sufficiently good solution in a reasonable time, a decomposition technique can be used. In our previous research two decomposition heuristic methods were developed. Both of them exploit a mathematical programming approach to solve a subproblem. The primary research aimed at the possibility of using the proposed methods for practical largescale problem instances was presented in [9] and [14]. 


\section{Solution Methods - Decomposition Heuristics Using Mathematical Programming}

The principle of a decomposition technique is simple: if the problem cannot be optimised as a whole, optimise it in parts. The approach can be used for every problem that can be divided into subproblems. Then every improvement of the subproblem corresponds to an improvement of the solution of the whole problem. Location problems meet this condition.

\subsection{Lopt Heuristic}

The first decomposition heuristic is based on the approach proposed by Taillard and published formerly under the name of POPMUSIC [24], and later in [25] as local optimization method (LOPT). In this paper the later notation is used.

To make the problem tractable, its size is reduced before the optimization. The goal is to eliminate the variables which are less likely to belong to a good or optimal solution. The reduction is performed in several steps. First, the set $I$ of 2,916 possible locations of stations is reduced. A new set $\bar{l}$ contains 2,282 candidate locations and consists of all the municipalities with the existing EMS stations defined by the official regulations, and all the other municipalities with at least 300 inhabitants. Second, one or more stations are placed a priori in large cities with more than 25,000 inhabitants, since 25,000 persons is a capacity limit of one ambulance (according to the analysis of the Slovak EMS system [3]). The number of stations $k_{j}$ that must be open in the municipality $j \in J$ we get by dividing the number of inhabitants by the capacity limit: $k_{j}=\left[b_{j} / 25,000\right]$. At the same time, the demand of the municipality $j$ is adjusted to the new value $\bar{b}_{j}=b_{j}-k_{j} \cdot 25,000$. The total number of stations placed in large cities before the optimization is $k=\sum_{j \in J} k_{j}$ ( $k=50$ in the case study). The number of stations to be located $(p=273)$ is reduced by this value leading to the new number $\bar{p}=p-k=223$. The set $\bar{l}$ and parameters $\bar{b}_{j}$ and $\bar{p}$ are the inputs to the Lopt heuristic. Since $\bar{b}_{j}<25,000$ for every $j \in J$, the heuristic places one station at the most in the candidate location $j$.

Further elimination of variables concerns the variables $\boldsymbol{x}$ and is based on the assumption that patients will not be served by the ambulances that are too far away. That is why only those variables $x_{i j}$ remain in the model for which the coefficient $t_{i j}$ is less than the predefined threshold. The threshold is defined by the value $t^{\text {limit }}=\alpha \cdot t^{\max } / \sqrt{\bar{p}}$ where $t^{\max }=\max \left\{t_{i j}: i \in \bar{I}, j \in J\right\}$ and $\alpha$ is a parameter. In the Slovak road network we have $t^{\max }=279$ minutes. Thus for $\alpha=1.5$ we get the threshold $t^{\text {fimit }}=26$ minutes. All these measures reduce the number of variables by $94 \%$. However, we still have 431,569 bivalent variables, and the use of a decomposition heuristic is justified.

The Lopt heuristic starts with the initial location of $\bar{p}=223$ stations that is computed by an IP solver running in a limited time. The initial locations are denoted as temporary and inserted into the set $C$. Then a temporary station is randomly selected. This selected station, together with a few of its closest stations and municipalities allocated to them in the current solution, form a subproblem with $r$ stations, which is considerably smaller than the initial location problem (see Fig. 1). The location of $r$ stations is optimized by using an IP solver. If a better location is found, all these stations remain temporary; otherwise the first station is removed from $C$. Then a new station is randomly selected and the process repeats until $C$ is empty.

\subsection{Decomp Heuristic}

The second heuristic denoted as Decomp is also based on the domain decomposition. But in contrast to the Lopt heuristic, the decomposition is performed at the beginning of the solution process. The territory is decomposed into administrative regions. It means that the set $I$ (remember $I=J$ ) is divided into a few disjunctive subsets. Each subset includes all municipalities of one of eight Slovak administrative regions. The size of the subsets ranges between 87 (Bratislava Region) and 664 municipalities (Prešov Region). The subsets define eight separate $p$-median problems (1) - (7) corresponding to the particular regions. The constant $p$ in every problem is set in order to preserve the current number of stations in the given region. The problems are solved separately. By the union of their solutions we obtain locations of all stations in the Slovak Republic.

The Decomp heuristic consists of the following four phases:

1. The location of $p$ stations is computed by solving the uncapacitated $p$-median 


\section{Fig. 1: A subproblem with several centres and municipalities allocated to them}

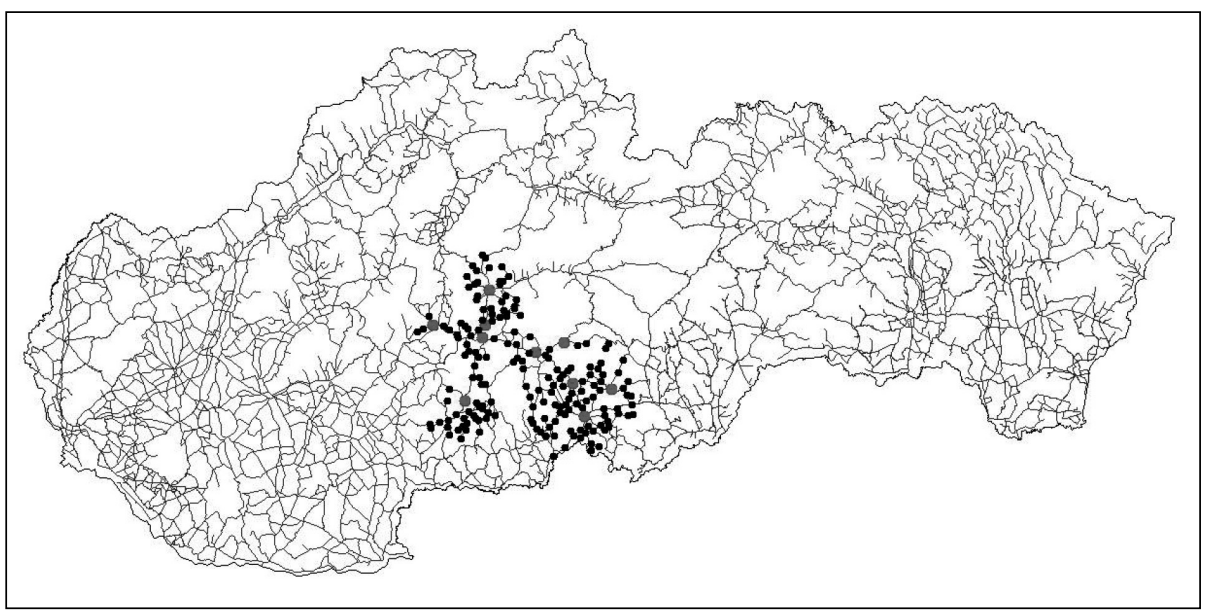

Source: own

problem (1) - (3), (5), (7) with the variables $y_{i} \in\{0,1\}$ for $i \in I$. Ad interim the constraints (4) are eliminated. Let $B_{i}=\sum_{j \in J} b_{j} x_{i j}$ be the number of inhabitants of the nearest municipalities $j$ which are served by the ambulance in the centre $i$.

2. The value $B_{i}$ represents the demand allocated to the centre $i$. It can be greater or less than the capacity limit $Q$ of an ambulance. To provide additional capacity in the centres with high demand, stations with small demand $\left(B_{i}<<Q\right)$ can be closed and relocated to the centres with high demand $\left(B_{i} \gg Q\right)$. In this step we decide on the number $p_{1}$ of stations which can be relocated.

3. The new location of $p-p_{1}$ stations is computed regardless of the capacity constraints. Let $I^{*}$ denote the set of new station locations with the demand $B_{i}$ allocated to them.

4. Now free $p_{1}$ stations can be relocated among the centres $i \in I^{*}$ by solving a new mathematical programming problem (8) (11). The variable $z_{i}$ indicates how many of relocated stations will be placed at the centre $i \in I^{\star}$. We introduce a new variable $w$ that represents a lower bound on the number of stations in a centre $i$ that share the demand $B_{i}$. The mathematical model maximizes the value $w$ and results in a new number $y_{i}$ of stations that consists of one station located in phase 3 and $z_{i}$ relocated stations.

$$
\begin{aligned}
& \text { Maximise } w \\
& \text { Subject to } \sum_{i \in I^{*}} z_{i} \leq p_{1} \\
& z_{i}+1 \geq B_{i} \cdot w \text { for } i \in l^{*} \\
& z_{i} \in Z_{0}^{+} \quad \text { for } i \in I^{*}
\end{aligned}
$$

The ability of the Decomp method to find a better station location is limited due to the fact that the number $p$ of stations for each subproblem is bound by the existing EMS stations in the given region. Therefore in the following research we tried to improve our solution by the adjustment of the input parameters of the Decomp heuristic. We used the results of the Lopt method as input data for the Decomp method as follow: from the Lopt solution we identified the number of stations for each of the Slovak regions and then found an improved location in the region by the Decomp method. For the time being, we call this procedure Lopt-Decomp.

The Lopt, Decomp and Lopt-Decomp procedures were implemented in the visual development environment Xpress-IVE using 
the solver Xpress-Optimizer v2.2.3 [8]. The experiments were performed on a personal computer equipped with the Intel Core i7 processor with $1.60 \mathrm{GHz}$ and $8 \mathrm{~GB}$ of RAM. The computation time did not exceed 25 minutes for Decomp and 217 minutes for the Lopt method.

\section{Evaluation of the Alternative Deployments}

Each of three described methods (Lopt, Decomp and new Lopt-Decomp) results in a different location of 273 stations. Each location is represented by the components of the output vector $\boldsymbol{y}^{*}$. The value $y_{i}>0$ indicates the number of stations located in the centre $i \in I$. The vector $\boldsymbol{y}^{*}$ is the input for the evaluation of the alternative deployments and their comparison mutually and with the current situation in the Slovak Republic.

The evaluation is based on the assumption that every municipality is served by its closest ambulance. The assignment of municipalities to centres can be quickly computed by solving the following allocation problem:

$$
\begin{array}{lll}
\text { Minimise } & \sum_{i \in l} \sum_{j \in J} t_{i j} x_{i j} & \\
\text { Subject to } & \sum_{i \in I} x_{i j}=1 \quad \text { for } j \in J \\
& x_{i j} \leq y_{i} \quad \text { for } i \in I, j \in J \\
& x_{i j} \in\{0,1\} \text { for } i \in I, j \in J
\end{array}
$$

Here $y_{i}$ are not any more variables but constants that give the number of stations located in the centre $i \in I$. The optimal solution of the problem (12) - (15) associates each centre $i$ with the subset of municipalities $J_{i}=\left\{j \in J, x_{j}=1\right\}$. Then the number of persons (potential patients) served by the centre $i$ is $B_{i}=\sum_{j \in J_{i}} b_{j}$ and the share of one ambulance located ain this centre is $B_{i} / y_{i}$.

Table 1 presents the basic characteristics of the proposed deployments of stations. The column Number of centres gives how many centres were chosen from 2,916 candidate locations. The column Number of differently located stations indicates how much the solution of the model differs from the current deployment of stations. We can see that in all solutions about $37 \%$ of 273 stations were located differently compared to the existing design. The column Total travel time of ambulances to patients represents the efficiency of the system measured as the total travel time of ambulances to all potential patients. The workload of ambulances expressed as the Number of people per ambulance is summarised in the last three columns. The average workload is identical in all designs because all solutions preserve the number of existing stations. Since our goal was to propose an even distribution of ambulances workload, the most important indicator was the range between the minimum and maximum workload. The greatest range can be observed in the case of the current deployment of stations. The most even distribution of workload was achieved by

\begin{tabular}{|c|c|c|c|c|c|c|}
\hline \multirow{2}{*}{$\begin{array}{l}\text { Method } \\
\text { for station } \\
\text { location }\end{array}$} & \multirow{2}{*}{$\begin{array}{l}\text { Number } \\
\text { of centres }\end{array}$} & \multirow{2}{*}{$\begin{array}{l}\text { Number } \\
\text { of differently } \\
\text { located } \\
\text { stations }\end{array}$} & \multirow{2}{*}{$\begin{array}{l}\text { Total travel time } \\
\text { of ambulances } \\
\text { to patients } \\
\text { [million person* } \\
\text { minutes] }\end{array}$} & \multicolumn{3}{|c|}{$\begin{array}{c}\text { Number of people } \\
\text { per ambulance } \\
\text { [in thousands] }\end{array}$} \\
\hline & & & & $\min$ & avg & $\max$ \\
\hline current & 209 & 0 & 14.06 & 1.3 & \multirow{4}{*}{19.8} & 70.9 \\
\hline Lopt & 233 & 104 & 11.86 & 5.3 & & 41.8 \\
\hline Decomp & 186 & 102 & 13.52 & 4.4 & & 40.6 \\
\hline Lopt-Decomp & 186 & 101 & 13.43 & 5.8 & & 33.6 \\
\hline
\end{tabular}
the combined Lopt-Decomp heuristic. These facts are as well demonstrated in Fig. 2.

\section{Tab. 1: Evaluation of the deployments of stations}




\section{Fig. 2: Number of people assigned to one ambulance}

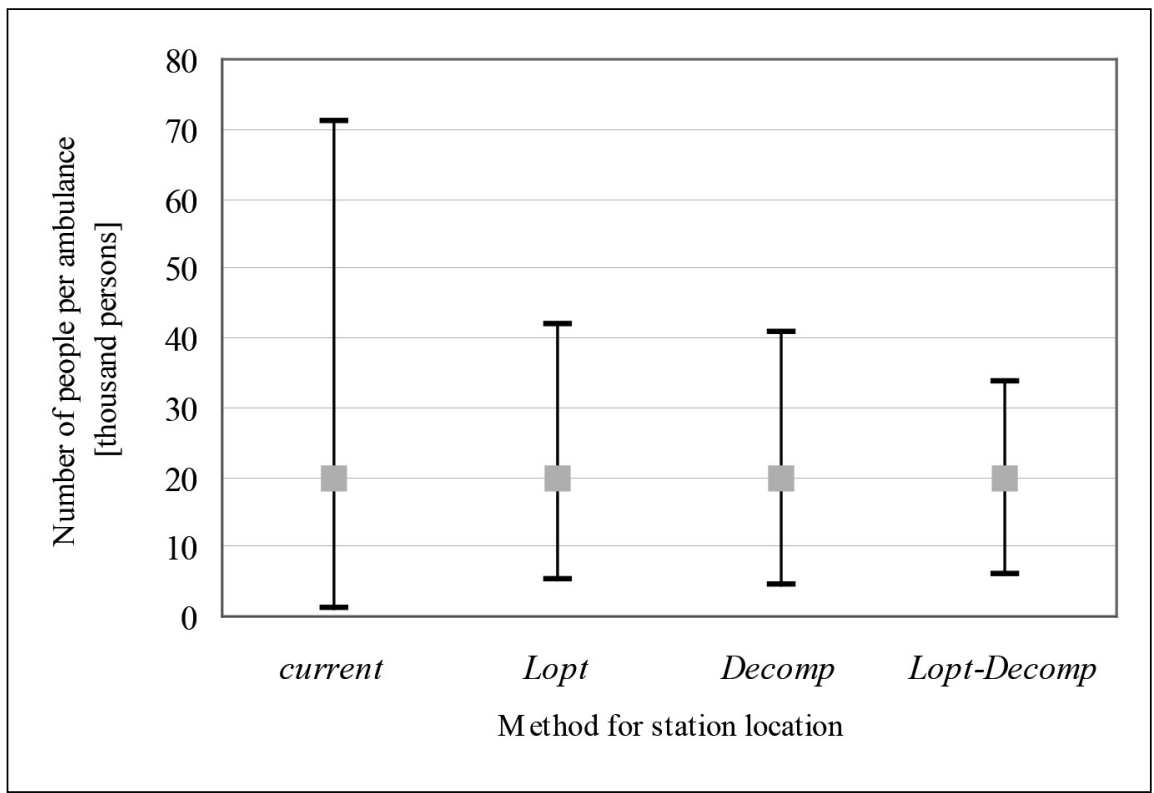

Source: own

However, the uniform distribution of workload may be achieved at the expense of long travel times of ambulances to some villages. Therefore we investigate the impact of the uniform workload on the transportation accessibility of municipalities. Table 2 gives how many people are accessible within a given time limit. All values about the population are given in \% of the total population of the Slovak Republic. The column Extreme contains the maximum travel time and the population of the village with the longest travel time. As it can be seen, the best accessibility was achieved by the Lopt heuristic.

The limitation of the applicability of the presented approach consists in the fact that we do not consider costs of redeployment of stations. To achieve a more fair design, the model changes substantially the current deployment of EMS stations (see the third column in Table 1). To implement proposed solutions would thus require to restructure the existing infrastructure considerably what might be too costly. If this issue is of importance, it can be practical to reduce the number of relocated stations, or to estimate the cost of closing and opening a station at site $i$ and require total investment costs to be in an allocated budget. To incorporate such constraints in the mathematical model, two new variables $u_{i}$ and $v_{i}$ must be supplemented, which indicate the number of closed and open stations at site $i$, respectively. They are defined by constraints (16) - (18), where $s_{i}$ is the current number of stations at site $i$.

$$
\begin{array}{ll}
u_{i} \geq s_{i}-y_{i} & \text { for } i \in I \\
v_{i} \geq y_{i}-s_{i} & \text { for } i \in I \\
u_{i}, v_{i} \in Z_{0}^{+} & \text {for } i \in I
\end{array}
$$

Let $n$ be the upper bound for the acceptable number of relocated stations. Then the constraint that limits the number of changes can be in the form:

$$
\sum_{i \in l} u_{i} \leq n
$$

This constraint might be replaced by another constraints requiring that the reconstruction of 


\begin{tabular}{|c|c|c|c|c|c|c|}
\hline \multirow[b]{2}{*}{$\begin{array}{l}\text { Method for } \\
\text { station location }\end{array}$} & \multicolumn{4}{|c|}{ Number of people [\%] } & \multicolumn{2}{|c|}{ Extreme } \\
\hline & $\begin{array}{l}\text { not more } \\
\text { than } \\
5 \text { minutes }\end{array}$ & $\begin{array}{c}5 \text { to } 10 \\
\text { minutes }\end{array}$ & $\begin{array}{l}10 \text { to } 15 \\
\text { minutes }\end{array}$ & $\begin{array}{l}\text { over } 15 \\
\text { minutes }\end{array}$ & $\begin{array}{c}\text { Travel } \\
\text { time } \\
\text { [minutes] }\end{array}$ & $\begin{array}{l}\text { Number of } \\
\text { people [\%] }\end{array}$ \\
\hline current & 77.01 & 19.74 & 2.98 & 0.27 & 29.5 & 0.008 \\
\hline Lopt & 82.10 & 15.50 & 2.20 & 0.19 & 26.0 & 0.005 \\
\hline Decomp & 78.93 & 18.40 & 2.49 & 0.18 & 29.2 & 0.005 \\
\hline Lopt-Decomp & 78.94 & 18.18 & 2.63 & 0.24 & 29.2 & 0.005 \\
\hline
\end{tabular}

the system will not exceed the total budget $q$. Let symbols $f_{i}^{c}$ and $f_{i}^{o}$ denote the cost of closing and opening a station at site $i$, respectively. Then the corresponding constraint is

$$
\sum_{i \in l}\left(f_{i}^{c} u_{i}+f_{i}^{o} v_{i}\right) \leq q
$$

The presented solution methods would be able to cope with such extension of the model (1) - (7). Another way how to improve the location model is to replace the capacity constraints (4) by an irregularity measure [19] applied to ambulances' workload.

\section{Conclusion}

In the paper, the problem of EMS stations location is formulated as a capacitated p-median problem. A new decomposition method is proposed. The comparison of the new Lopt-Decomp method with previously developed heuristics Lopt and Decomp is presented with regard to ambulances workload and transportation accessibility. The best results in terms of the distribution of workload were achieved by the Lopt-Decomp method, and in terms of the accessibility by the Lopt method.

However, these results are just the estimations of the real system performance because a deterministic mathematical programming model ignores the stochastic character of the modelled system. The best way how to estimate performance characteristics before the implementation of the solution in the real environment is to use a computer simulation model. Such a model of the EMS system was built within the current research [15], nevertheless, we do not have realistic data needed to calibrate the model. In the future we will endeavour to obtain data from responsible authorities and to verify the conclusions by means of a computer simulation.

This research was supported by the Slovak Research and Development Agency under project APVV-0760-11 "Designing of Fair Service Systems on Transportation Networks".

\section{References}

[1] ARAZ, C., SELIM, H., OZKARAHAN, I. A fuzzy multi-objective covering-based vehicle location model for emergency services. Computers \& Operations Research. 2007, Vol. 34, Iss. 3, pp. 705-726. ISSN 0305-0548. DOI: 10.1016/j.cor.2005.03.021.

[2] ARINGHIERI, R., CARELLO, G., MORALE, D. Ambulance location through optimization and simulation: the case of Milano urban area. Proceedings of the XXXVIII Annual Conference of the Italian Operations Society - Optimization and Decisions Sciences, 2007, pp. 1-29.

[3] BAHELKA, M. Analýza systému záchrannej zdravotnej služby po reforme [online]. Bratislava: Health Policy Institute, 2008 [cit. 2014-03-03]. Available from: http://www.hpi.sk/ hpi/sk/view/3795/analyza-systemu-zachrannejzdravotnej-sluzby-po-reforme.html.

[4] BREZINA, I., DUPAL', A., PEKÁR, J. Zelená a reverzná logistika ako nástroj zefektívnenia spal'ovania odpadu $v$ Slovenskej republike. Ekonomický časopis. 2011, Vol. 59, No. 2, pp. 132-147. ISSN 0013-3035.

[5] BROTCORNE, L., LAPORTE, G., SEMET, F. Ambulance location and relocation models. European Journal of Operational Research. 
2003, Vol. 147, Iss. 3, pp. 451-463. ISSN 03772217. DOI: $10.1016 / \mathrm{s} 0377-2217(02) 00364-8$.

[6] CHANTA, S., MAYORGA, M.E., MCLAY, L.A. Improving emergency service in rural areas: a bi-objective covering location model for EMS systems. Annals of Operations Research. 2014, Vol. 221, Iss. 1, pp. 133-159. ISSN 02545330. DOI: 10.1007/s10479-011-0972-6.

[7] COMBER, A.J., SASAKI, S., SUZUKI, H., BRUNSDON, C. A modified grouping genetic algorithm to select ambulance site locations. International Journal of Geographical Information Science. 2011, Vol. 25 , Iss. 5, pp. 807-823. ISSN 1365-8816. DOI: 10.1080/13658816.2010.501334.

[8] FICO ${ }^{T M}$ Xpress Optimization Suite [online]. [cit. 2011-10-10]. Available from: http://www. fico.com.

[9] GÁBRIŠOVÁ, L., JANÁČEK, J. Návrh rozmiestnenia staníc záchrannej služby v Žilinskom kraji. Sborník príspěvkư semináře Úlohy diskrétní optimalizace $v$ dopravní praxi 2013. Pardubice: Univerzita Pardubice, 2013. pp. 16-25. ISBN 978-80-7395-662-2.

[10] HENDERSON, S.G., MASON, A.J. Ambulance service planning: Simulation and Data Visualisation. In: BRANDEAU, M.L., SAINFORT, F., PIERSKALLA, W.P. (Eds.). Operations Research and Health Care: A Handbook of Methods and Applications. Springer, 2004. pp. 77-102. ISBN 978-1-40207629-9.

[11] HOGAN, K., REVELLE, C. Concepts and applications of backup coverage. Management Science. 1986, Vol. 32, No. 11, pp. 14341444. ISSN 0025-1909. DOI: 10.1287/ mnsc.32.11.1434.

[12] INGOLFSSON, A., BUDGE, S., ERKUT, E. Optimal ambulance location with random delays and travel times. Health Care Management Science. 2008, Vol. 11, Iss. 3, pp. 262-274. ISSN 1386-9620. DOI: 10.1007/s10729-0079048-1.

[13] JANÁČEK, J., et al. Navrhovanie územne rozlahlých obslužných systémov. Žilina: EDIS - Vydavatel'stvo Žilinskej univerzity, 2010. 404 p. ISBN 978-80-554-0219-2.

[14] JÁNOŠíKOVÁ, L'., ŽARNAY, M. Location of emergency stations as the capacitated p-median problem. Proceedings of the International Scientific Conference Quantitative Methods in Economics - Multiple Criteria Decision Making XVII. Bratislava: Ekonóm, 2014. pp. 116-122. ISBN 978-80-225-3868-8.
[15] JÁNOŠÍKOVÁ, L'., ŽARNAY, M., MÁRTON, P., KVET, M. Modely pre umiestnenie staníc záchrannej zdravotnej služby a ich porovnanie pomocou počítačovej simulácie. In: Sborník príspěvků semináře Úlohy diskrétní optimalizace $v$ dopravní praxi 2013. Pardubice: Univerzita Pardubice, 2013. pp. 52-61. ISBN 978-80-7395-744-5.

[16] JEŽEK, B., VANĚK, J., PROCHÁZKA, $M$. Estimation of response time for ground ambulance transport. Journal of System and Management Science. 2011, Vol. 1, No. 5, pp. 69-77. ISSN 1816-6075.

[17] LAWSON, C., NEMEC, J., ŠAGÁT, V. Health care reforms in the Slovak and Czech Republics 1989-2011: The same or different tracks? E+M Ekonomie a Management. 2012, Vol. 15, Iss. 4, pp. 19-33. ISSN 1212-3609.

[18] MARIANOV, V., SERRA, D. Location problems in the public sector. In: DREZNER, Z., HAMACHER, H.W. (Eds.). Facility Location: Applications and Theory. 1st ed. Heidelberg: Springer-Verlag Berlin, 2004. ISBN 3-54021345-7.

[19] PEŠKO, Š., ČERNÝ, J. Uniform splitting in managerial decision making. E+M Ekonomie a Management. 2006, Vol. 9, Iss. 4, pp. 67-71. ISSN 1212-3609.

[20] PIRKUL, H., SCHILLING, D. The capacitated maximal covering location problem with backup service. Annals of Operations Research. 1989, Vol. 18, Iss. 1, pp. 141-154. ISSN 0254-5330. DOI: 10.1007/BF02097800.

[21] REVELLE, C.S., EISELT, H.A. Location analysis: A synthesis and survey. European Journal of Operational Research. 2005, Vol. 165, Iss. 1, pp. 1-19. ISSN 0377-2217. DOI: 10.1016/j.ejor.2003.11.032.

[22] SASAKI, S., COMBER, A.J., SUZUKI, H., BRUNSDON, C. Using genetic algorithms to optimise current and future health planning - the example of ambulance location. International Journal of Health Geographics. 2010, Vol. 9, Iss. 4. ISSN 1476-072X. DOI: 10.1186/1476072X-9-4.

[23] SILVA, P.M.S., PINTO, L.R. Emergency medical systems analysis by simulation and optimization. In: Proceedings of the 2010 Winter Simulation Conference, 2010. pp. 24222432. ISBN 978-1-4244-9866-6.

[24] TAILLARD, E.D., VOß S. POPMUSIC: Partial Optimization Metaheuristic Under Special Intensification Conditions. In: RIBEIRO, C.C., HANSEN, P. (Eds.). Essays and Surveys 
in Metaheuristics. Springer, 2001. pp. 613-629. ISBN 978-0-7923-7520-3.

[25] TAILLARD, E.D. Heuristic methods for large centroid clustering problems. Journal of Heuristics. 2003, Vol. 9, Iss. 1, pp. 51-73. ISSN 1381-1231. DOI: 10.1023/A:1021841728075.

prof. Ing. L'udmila Jánošíková, PhD. University of Žilina Faculty of Management Science and Informatics

Department of Mathematical Methods and Operations Research Ludmila.Janosikova@fri.uniza.sk
Mgr. Lýdia Gábrišová, PhD.

University of Žilina

Faculty of Management Science and Informatics

Department of Mathematical Methods and Operations Research Lydia.Gabrisova@fri.uniza.sk

Ing. Bruno Ježek, PhD. University of Hradec Králové Faculty of Informatics and Management Department of Informatics and Quantitative Methods Bruno.Jezek@uhk.cz 


\section{Abstract}

\section{LOAD BALANCING LOCATION OF EMERGENCY MEDICAL SERVICE STATIONS}

\section{Ludmila Jánošíková, Lýdia Gábrišová, Bruno Ježek}

When we want to design a successful and efficient emergency medical system, the crucial task is to determine the number of ambulances operating in a given region and the deployment of stations where the ambulances are kept. In the Slovak Republic, the number and locations of stations are specified by the Ministry of Health for the whole state territory. In the Czech Republic, the network of stations is established by the local authority for each administrative region. Due to geographical and population diversity, there are significant differences in population served by individual ambulances. Assuming that the number of ambulances is given, we want to investigate whether a different location of the ambulances might result in a more even distribution of their workload and, consequently, shorter response time. The problem is modelled as a capacitated p-median problem and solved using mathematical programming. The capacitated p-median problem is known to be NP-complete. As a consequence, it cannot be solved to optimality even for moderate-sized problem instances. However, we face a large-scale problem instance consisting of almost 3,000 demand nodes. Therefore heuristic approaches need to be used to get a sufficiently good solution in an acceptable time. Two decomposition mathematical heuristics are described in the paper and a new heuristic method based on previously developed approaches is presented. A redeployment of existing EMS stations in the Slovak Republic is calculated using these methods. The results are compared mutually and with the current deployment. The benefits and limitations of the presented methodology are discussed.

Key Words: Emergency medical service, capacitated p-median problem, NP-hard problem, local optimization, integer programming, decomposition heuristics technique.

JEL Classification: C61, I18.

DOI: 10.15240/tul/001/2015-3-003 